\title{
CHILD FOCUSED ACTIVITIES IN SRI LANKA
}

\section{VINITHAMALI WICKRAMARATNE}

\begin{abstract}
Children are the human capital of the future. Recognising the importance of supporting the growth and development of children, it is imminent that a national plan of action for children of Sri Lanka is formulated. An analysis of child focused activities undertaken at present in the country could invariably provide useful guidance in formulating such a plan of action for children. The paper attempts to review the nature of child focused activities and the problems encountered in the implementation of relevant programmes. Further an attempt is made to review the nature of the programmes conducted for parents. The data is obtained from a survey conducted during March to May 2000, on a sample of organisations engaged in child focused activities in Sri Lanka. The findings reveal that child focused activities of a diverse nature contribute to the survival, protection, care and development of children in Sri Lanka during their growing years. The absence of a live network facilitating relationships among the organisations involved in child focused activities is highlighted in the study and it is observed that this tends to limit the possibilities of moving towards intergrated programming.
\end{abstract}

\section{INTRODUCTION}

The child's well-being is closely linked to the well-being of the family: Parents as first teachers of their children bring about qualitative improvements in the development of the child. The impact of parental care giving, goes a long way in augmenting children's development and life-long learning.

Recognising the importance of supporting the growth and development of children, both governmental and non governmental organisations in Sri Lanka have undertaken many and varied child focused activities. The Government of Sri Lanka has acted in conformity with the Convention on the Rights of the Child and adopted a national plan of action for Sri Lanka's children. Keeping in line with this plan of action, we need to formulate a national plan of action on early childhood 
care and development. In the context of these developments, it is desirable that the activities presently undertaken by the organisations engaged in child focused activities be explored and reviewed.

This paper therefore explores the type and nature of the activities undertaken by the organisations presently engaged in child focused activities in Sri Lanka and the problems encountered by these organisations in the successful implementation of the programmes. An attempt is also made to review the nature of the programmes for parents, conducted by these organisations.

\section{THE STUDY}

The information presented is essentially based on a survey conducted during March to May 2000, on a sample of organisations presently engaged in child focused activities in Sri Lanka. The sample consisted of 201 organisations selected at random from a complete list of 254 organisations compiled in a directory of organisations engaged in child focused activities in Sri Lanka (INASIA 1999)

Data was collected from organisations engaged in child focused activities that responded to a questionnaire mailed to such organisations. In order to gather information on the problems encountered in the successful implementation of the programmes, interviews were conducted with the programme developers of ten organisations from among the 83 organisations that responded to the mailed questionnaire. The organisations included in the study fall into the following types:

$\begin{array}{lll}\text { Category A } & * & \text { Government Organisations } \\ & * & \text { Semi-Government Organisations }\end{array}$

Category B * Diplomatic Missions

* United Nations Organisations

* Embassies

* Donor Organisations 
Category C * a) Foreign/International Organisations based in Sri Lanka

* b) Local Organisations

Departments of Labour, Probation and Child Care Services, Social Services, Ministry of Health, the National Child Protection Authority, the National Institute of Health Sciences, Plantation Housing and Social Welfare Trust and the Police Department fall within Category A.

The Swedish International Development Co-operation Agency, the International Programme for the Elimination of Child Labour, United Nations Children's Fund, United Nations High Commission for Refugees, and the World Health Organisation belong to Category B.

Category C consists of non-governmental organisations, voluntary organisations, charitable organisations, social service organisations, associations, trade unions, co-operatives, religious organisations and other organisations and groups engaged in child focused activities in Sri Lanka. Organisations in Category C consist of both foreign/international organisations based in Sri Lanka as well as local organisations. Save the Children (Norway), Save the Children (UK), SOS Children's Villages of Sri Lanka, Plan International Sri Lanka and the Christian Children's Fund are examples of international organisations based in Sri Lanka. The Sarvodaya Early Childhood Development Unit, Samadeepa Samaja Kendraya, Samasevaya Sithuwama Training and Education and Development Organisations are some of the local organisations engaged in child focused activities.

The representation of each type of organisation in the total population is given in Table 1 . Number and \% responded by type of organisation is given in Table 2 . Number and \% responded by province is given in Table 3 . 
Table 1: Number and \% of each type of organisation in the total population.

\begin{tabular}{ccc}
\hline Types of Organisation & Number & $\%$ \\
\hline A & 8 & 3.2 \\
B & 5 & 2.0 \\
C & 241 & 94.8 \\
Total & $\mathbf{2 5 4}$ & $\mathbf{1 0 0}$ \\
\hline
\end{tabular}

Table 2: Number and \% responded by type of organisation.

\begin{tabular}{ccc}
\hline Types of Organisation & Number & $\%$ \\
\hline A & 5 & 6.03 \\
B & 2 & 2.40 \\
C & 76 & 91.57 \\
Total & $\mathbf{8 3}$ & $\mathbf{1 0 0}$ \\
\hline
\end{tabular}

Table 3: Number and \% responded by Province

\begin{tabular}{lrr}
\hline \multicolumn{1}{c}{ Province } & Number & $\%$ \\
\hline 1. Western & 48 & 57.83 \\
2. Eastern & 9 & 10.84 \\
3. Northern & 3 & 3.61 \\
4. Southern & 5 & 6.02 \\
5. North Western & 4 & 4.81 \\
6. North Central & 1 & 1.20 \\
7. Central & 9 & 10.84 \\
8. Uva & 1 & 1.20 \\
9. Sabaragamuwa & 3 & 3.61 \\
Total & $\mathbf{8 3}$ & $\mathbf{1 0 0}$ \\
\hline
\end{tabular}


The organisations engaged in child focused activities serve the major ethnic groups, namely Sinhala, Tamil and Muslim. The ethnic groups served by the organisations could be categorised as shown in Table 4.

\section{Table 4: Ethnic groups served by organisations}

\begin{tabular}{lc}
\hline Ethnic Group & $\begin{array}{c}\text { Number of organisations } \\
\text { serving each ethnic group }\end{array}$ \\
\hline Sinhala only & 18 \\
Tamil only & 8 \\
Muslim only & 1 \\
Sinhala \& Tamil only & 14 \\
Sinhala \& Muslim only & 2 \\
Tamil \& Muslim only & 2 \\
Sinhala, Tamil \& Muslim only & 17 \\
All ethnic groups & 21 \\
Total & 83 \\
\hline
\end{tabular}

\section{DISCUSSION}

\section{Type and nature of activities}

It is revealed that the activities undertaken by the said organisations cater to children from birth to twelve years of age. These activities are diverse in nature, yet they are all geared to the growth and development of the child during infancy and childhood. Hence, it appears unrealistic to compartmentalise the activities. However, for the purpose of analysis, the activities undertaken are classified into six major areas, namely education, health and nutrition, protection, rehabilitation, counseling/ therapeutic treatment and others.

Table 5 shows the number and \% of activities in each category in relation to the specified age ranges. 


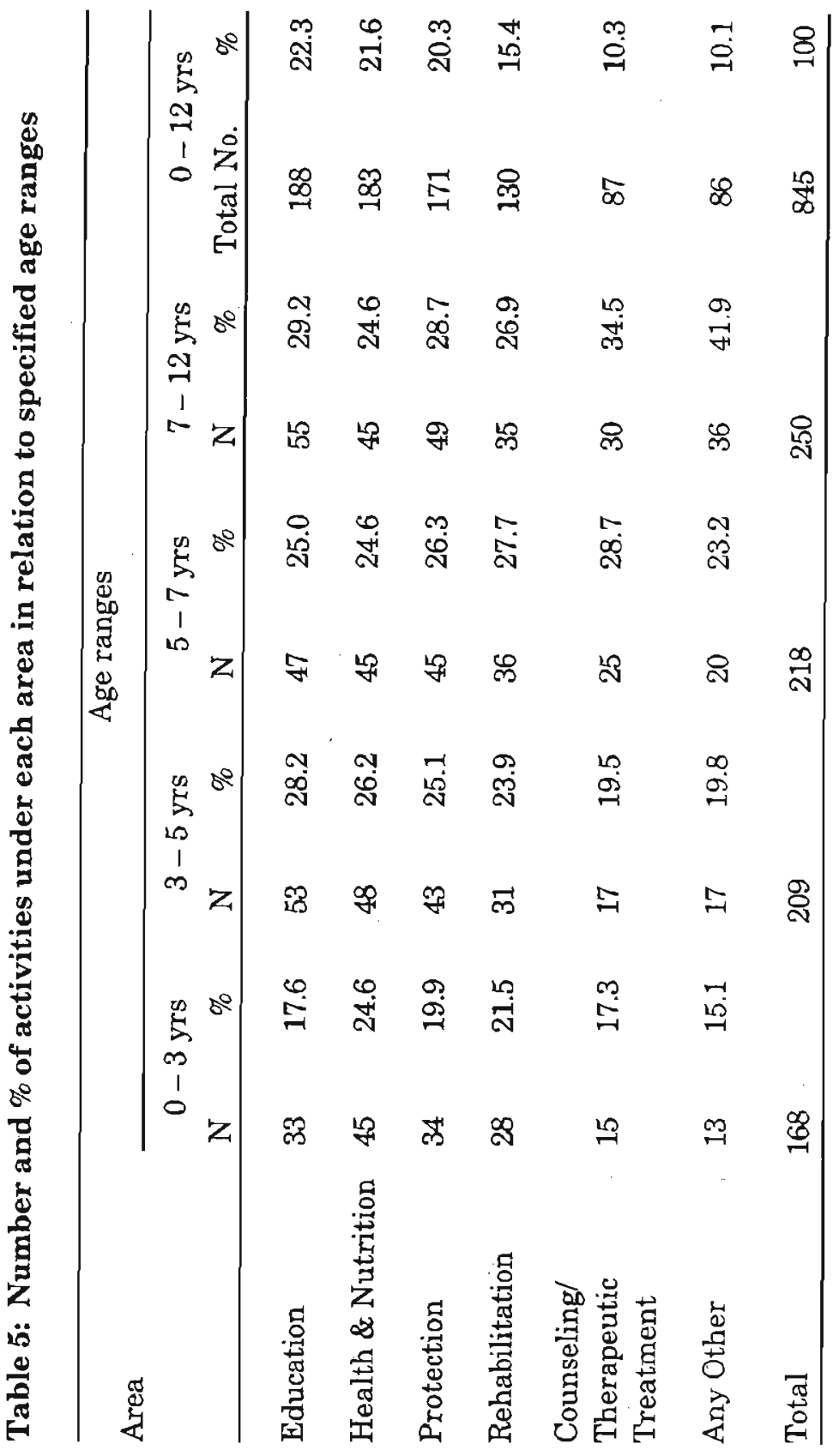




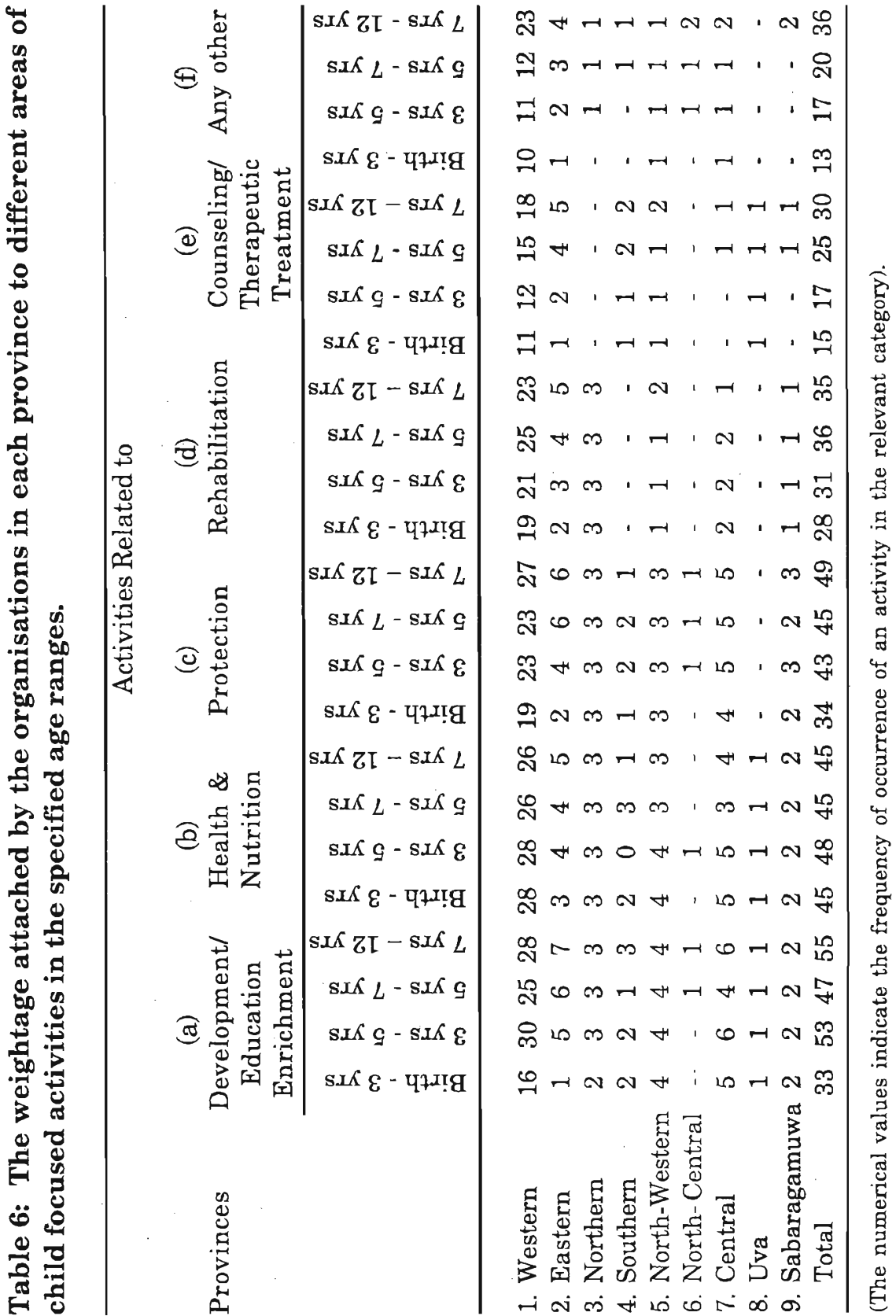


Table 6 explains the weightage attached by the organisations to child focused activities (related to major areas) in each province in the specified age ranges.

\section{Education}

All activities undertaken with the view to providing care and development of children and thereby enhancing their capacity for systematic training and instruction are treated in this paper in the area, 'education'.

Activities related to 'education' occupy a predominant position in the agenda of many organisations. Out of the total number of activities $22.3 \%$ is related to this area. Of the activities related to this area, the focus on children of the age group birth to three years is limited to $17.6 \%$ and appears to be relatively low. The main activities undertaken include the provision of creche/day care facilities, mental and physical stimulation through play groups and the training of parents and caregivers.

Table 4 shows that in some of the provinces such as North Central and Uva the focus on children of this age group with regard to these activities is nil or negligible.

Conducting and maintaining pre-schools, maintaining day care centres, conducting awareness programmes on early childhood care for parents and also conducting awareness programmes for volunteer teachers are the main activities undertaken, focusing on children in the age group of three to five years. The activities so conducted for the age group three to five years constitute nearly $28.2 \%$ in the area 'education' (Table 5).

The nature of the activities that focus on children in the two age groups, five to seven and seven to twelve appear to be similar. Maintenance of day care centres for children after school hours, the conducting of literacy classes for street children and children from slums, provision of basic education facilities and free tuition for school dropouts, 
the organising of children's clubs and parental awareness programmes, and the construction and rehabilitation of school buildings are the main activities undertaken.

In addition, some organisations distribute free school uniforms and books to needy children and conduct seminars and awareness programmes on child rights in the interest of children in the age group seven to twelve years.

Of the activities related to 'education' $25 \%$ focus on children in the age group five to seven and $29.2 \%$ focus on children in the age group seven to twelve years. Hence, the percentage of programmes related to 'education' undertaken in respect of children above five years of age appears to be higher than the percentage of programmes related to 'education' undertaken in respect of children from birth to five years.

\section{Health and Nutrition}

Health care and adequate nutrition also form major aspects of overall development of children during the growing years.

Of all child focused activities, $21.6 \%$ appear to be related to health and nutrition. The nature of the activities undertaken in respect of children in the age group, from birth to three years and from three to five years appear to be almost the same. Growth monitoring, medical camps and health clinics - especially for health screening and care, immunization programmes, distribution of milk, kola kenda etc., support for better health care and nutrition status of mothers are the main programmes implemented in respect of children upto five years.

As children grow older, the emphasis especially on immunization programmes and distribution of milk tends to be reduced. The other programmes continue to be implemented even for older children. New activities such as the conducting of ENT, eye and dental clinics, general health care through clinics, organising of recreational and sports activities, conducting programmes for mothers of malnourished children, conducting awareness programmes for mothers on child abuse and family 
planning appear to be undertaken in the interest of children in the age groups five to seven and seven to twelve years.

\section{Protection}

There has been a growing recognition of the need to ensure that the children are protected from child/sexual abuse, exploitation at work and other circumstances that may deprive them of normal development. Of all child focused activities, 20.3\% appear to be related to protection. The nature of the activities related to protection does not appear to be age-related.

Programmes related to protection attempt to support the improvement of standards in day care centres especially in the plantation sector so as to ensure safe environments for children to rest and play, and to create awareness among mothers on child abuse, child labour and child rights. In addition, a few non-governmental organisations campaign against child abuse and conduct programmes for selected experienced matrons of child care centres, with a view to ensuring the prevention of child abuse.

In addition, limited activities are organised by a few nongovernment organisations for slum/shanty children, children of low income families, street/homeless/beach children, war/conflict affected children and single parent children.

\section{Rehabilitation}

Of all child focused activities a relatively low percentage of programmes (15.4\%) are related to rehabilitation. As shown in Table 5, programmes on rehabilitation in respect of all age groups are nil or negligible in certain provinces. Activities related to rehabilitation appear to be essentially focused on deaf children, visual and hearing impaired children and physically disabled children. The main objective of programmes related to rehabilitation of disabled children is to provide artificial limbs, spectacles, hearing aids etc. Three organisations, 
however, appear to conduct skill based activities as well, for physically disabled children.

\section{Counseling/Therapeutic treatment}

Child focused activities on counseling/therapeutic treatment are limited (10.3\%) and not age-related. Counseling programmes for children (above 7 years) and for parents, psychological support services for sexually abused children and counseling for the prevention of suicide are the three major activities undertaken.

As shown in Table 6, programmes related to counseling/ therapeutic treatment are negligible or nil in a majority of the provinces.

Organising children's societies, art competitions, quiz programmes, exhibitions, sports meets and providing Sunday-school education could be listed as child-focused activities not specifically included under any of the categories reviewed above. These constitute $10.1 \%$ of the total number of child-focused activities recorded. A relatively high percentage of activities in this category (41.9\%) appear to focus on the age group seven to twelve years.

\section{Programmes for parents}

Programmes for parents conducted by the organisations engaged in child focused activities attempt to empower the parents, more particularly the mothers, with a view to enabling them to play an efficient role as caregivers. A majority of the programmes are designed to create awareness and educate mothers. The main areas focused upon are, maternal health, child health, child nutrition, the importance of breast feeding, pre-natal care, post-natal care, child abuse and home based stimulation for children during early childhood and in primary school.

Marriage counseling and family life education are the main items on the agenda of counseling programmes organised for parents by these 
organisations. A few organisations conduct programmes on drug/alcohol rehabilitation as well.

In addition to the programmes mentioned above for parents, some of the programmes conducted by the organisations engaged in child focused activities; aim to strengthen the families economically as well. Income generating projects ane organised by a few organisations, while a few others provide vocational training for parents to develop their capácity for self-employment. Financial help in the form of loans and grants are also extended to needy parents by a few organisations. The majority of the organisations involved in these activities are nongovernment organisations.

Programmes conducted for parents of young children, cover a wide range of activities. However, the study reveals that other than in the Western and the Eastern provinces, the importance attached to programmes for parents is negligible.

\section{PROBLEMS ENCOUNTERED}

The problems encountered by the ten organisations interviewed, appear to be common. It is the degree of the impact of each problem on the successful implementation of programmes that differs.

The lack of adequate funds is the most pressing problem that impedes the successful implementation of programmes. Both the government and the nongovernment sectors are confronted with this pressing problem. Most programmes are being funded for a specific period of time and the activities tend to be curbed when funds are exhausted. The majority of pregrammes managed by NGOs do not have the capacity to raise funds: Three organisations stated that although they are expected to raise funds, their capacity to do so is limited.

Due to the limited monitoring mechanisms adopted and the lack of follow-up action, a majority of the organisations are unable to get proper feedback on the activities undertaken. Lack of adequate funds is the causal factor for this state of affairs. 
Inadequacy of trained personnel to handle different components of childhood development programmes also tends to affect the successful implementation of the programmes. Each of the ten organisations has a core group of trained personnel to handle the programmes. These organisations are in fact in the process of developing staff capacity to organise and implement child focused activities. But taking into consideration the necessity to meet the demands of distant rural areas, the number of persons involved in child focused activities needs to be increased and their capacity further enhanced.

In the absence of a national plan of action on early childhood care and development, possibilities of getting the services of experts to train and retrain personnel in the said organisations on a regular basis are limited, both in government organisations and in non government organisations. For example in areas like Moneragala, facilities available to enrich the experiences and update the knowledge of grassroot level workers are negligible. Hence, as observed by the organisations, the quality of training and updating of knowledge of persons involved in child focused activities tend to suffer.

In addition, in rural areas and urban slum areas where most people live in poverty and where the education level of parents too tends to be low, their awareness of the necessity to give priority to the developmental needs of children is also very low. Parents are too busy earning their daily bread, and therefore, their participation in childfocused programmes is not adequate. It was observed by four organisations that parents tend to participate actively in such programmes only when they receive money for participation. Hence, factors like the location of the programme and the socio-economic level of parents have an impact on attempts to reach children and parents especially in impoverished environments.

However, two organisations expressed the view that it is possible to bring about a positive change in the attitudes of parents on the need to give priority to the developmental needs of their children, provided that programmes be conducted for parents in small groups and on a regular basis. 
The problems encountered by the organisations appear to be inter-related and complex and ideally may be resolved by a national plan of action .

\section{SUMMARY AND CONCLUSION}

Government and semi-government organisations, diplomatic missions, United Nations organisations, embassies and donor organisations, international organisations based in Sri Lanka and local nongovernmental organisations contribute to ensuring the survival, protection, care and development of children in Sri Lanka. In line with the pattern throughout Asia and the Pacific, non-governmental organisations have the largest number of child focused programmes in Sri Lanka as well.

It is encouraging to note that diverse activities are undertaken in Sri Lanka for the care and development of children during their growing years - i.e. from birth to twelve years. The nature of the activities is very similar to child focused activities elsewhere in the Asian region. In Sri Lanka too a few organisations in the governmental and in the non-governmental sector are responding to emerging critical issues such as street children, child rights and child protection.

The percentage of programmes conducted for the age group from birth to five years is relatively less $(44.6 \%)$ compared to the higher percentage (55.4\%) of programmes for age group five to twelve years. Of all programmes, only $19.8 \%$ focus on children in the age group from birth to three years. The low emphasis placed on activities for children from birth to five years, is a concern of high priority in future programming for young children.

Furthermore, the absence of a live network facilitating relationships among the organisations involved in child focused activities, tends to limit the possibilities of moving towards integrated programming, which is necessary to ensure maximum benefits for children in their overall development. Hence, steps should be taken to establish linkages, between agencies and organisations - governmental 
and non-governmental - that offer complementary services. Both research and experience suggest that programmes for young children would ensure maximum benefit when the programmes are multidimensional and seek to integrate their education, health, nutrition and psycho-social well being.

In the development and implementation of programmes on childhood care and development it is important that progress is made at national level to recognise the role that NGOs can play.

Activities already undertaken by the organisations should be further strengthened with financial support and trained staff in child focused activities.

Grassroot level workers at these organisations could be equipped with basic skills in research on child focused activities. This will enable the organisations to bring about qualitative improvements in their programmes and to make the activities essentially 'child centred'.

The organisations engaged in child focused activities appear to serve all provinces, but seem to be inadequate for the Southern, North Central, Uva and Sabaragamuwa provinces. The largest number of programmes are located in the Western province. There is an urgent necessity to meet the diverse needs of young children in all other provinces as well. All three ethnic groups, Sinhala Tamil and Muslim are being served by the organisations engaged in child focused work. However, further studies need to be undertaken to review the adequacy of the activities.

The organisations engaged in child focused activities in Sri Lanka extend their services to ordinary children, children living in difficult circumstances as well as differently abled children. Nevertheless taking into consideration the nature and the limited extent of the activities undertaken for children living in difficult circumstances and differently abled children, it is necessary that programmes are further developed and implemented for all categories of children. 
The programmes for parents conducted by the organisations cover a wide range of activities and attempt to empower the parents, thereby enhancing their capacity to play a more efficient role as caregivers. But these programmes are confined to the Western and Eastern provinces, and need to be expanded to other provinces as well.

Parental involvement in child-focused activities should in fact be promoted island-wide. A child's well being is closely linked to the family. Hence, in order to achieve the targeted objectives of child focused programmes, it is necessary to ensure parental involvement. There is also a need to promote active public participation in order to achieve the desired goals of these programmes. The use of multi-media communication material could play an effective role especially in promoting active public participation.

The activities presently undertaken in Sri Lanka for the wellbeing of children and their parents are many and varied. But in the absence of proper direction at national level, it is questionable whether these child focused activities could ensure the total well-being of the child.

A holistic approch to child development with direction provided by a national policy, needs to be adopted, so that from conception, a child's right to survival, protection, care and optimal development is ensured.

\section{References}

A Directory of organisations engaged in child-focused activities in Sri Lanka. Initiative in Research and Education for Development in Asia (INASIA) 1999. 